\title{
Perovskite-like Metal Formates with Weak Ferromagnetism and as Precursors to Amorphous Materials
}

\author{
Xin-Yi Wang, Lin Gan, Shi-Wei Zhang, Song Gao*
}

Supporting Information

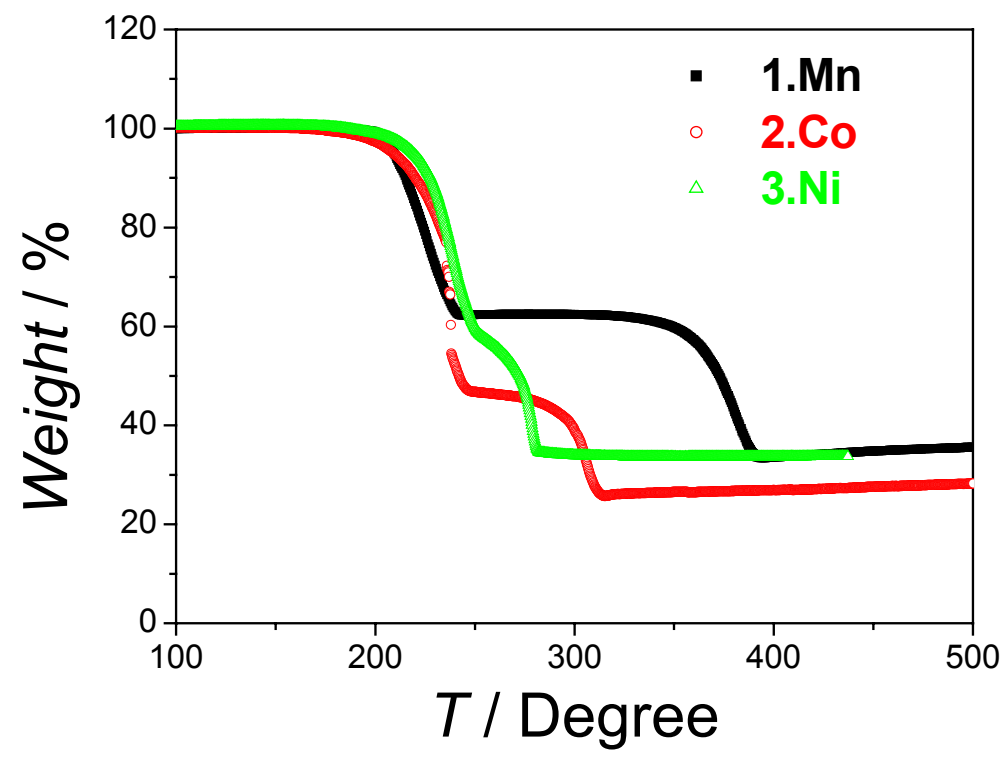

Figure S1 Thermogravimetric analysis (TGA) graph of $\mathrm{M}(\mathrm{CHOO})_{3}\left[\mathrm{NH}_{2}\left(\mathrm{CH}_{3}\right)_{2}\right](\mathrm{M}=$ $\operatorname{Mn}(\mathbf{1} \cdot \mathbf{M n}), \operatorname{Co}(\mathbf{2} \cdot \mathbf{C o}), \mathrm{Ni}(\mathbf{3} \cdot \mathbf{N i}))$ from room temperature to $500{ }^{\circ} \mathrm{C}$. 


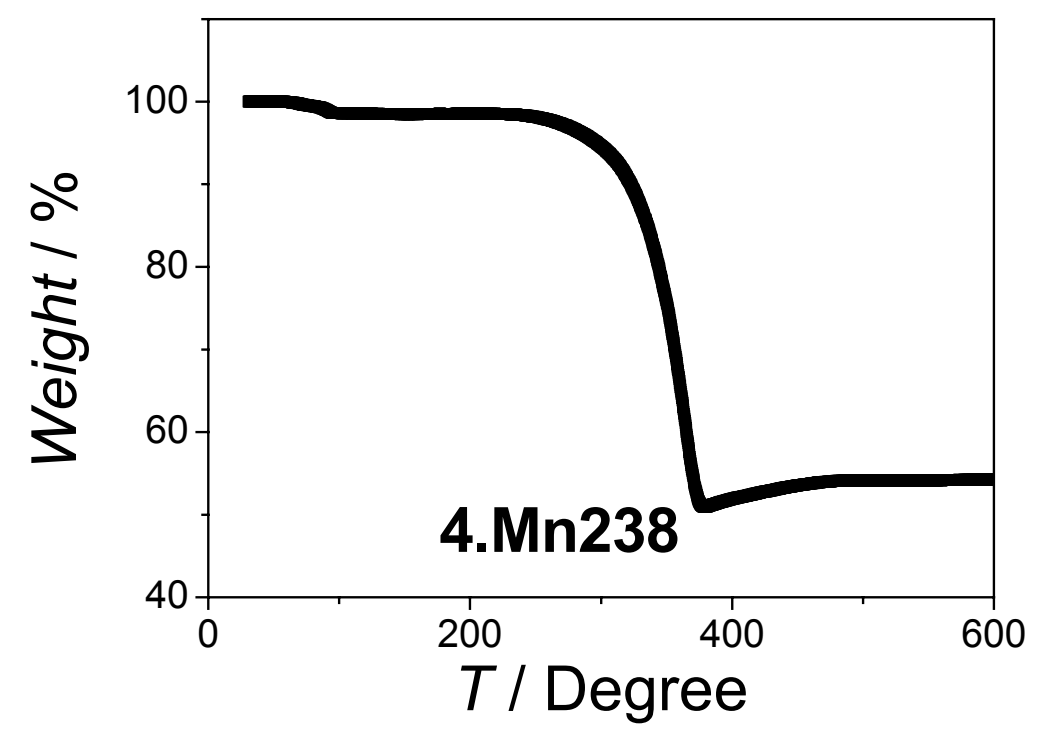

Figure S2 Thermogravimetric analysis (TGA) graph of $4 \cdot \mathbf{M n} 238$ from room temperature to $600{ }^{\circ} \mathrm{C}$.

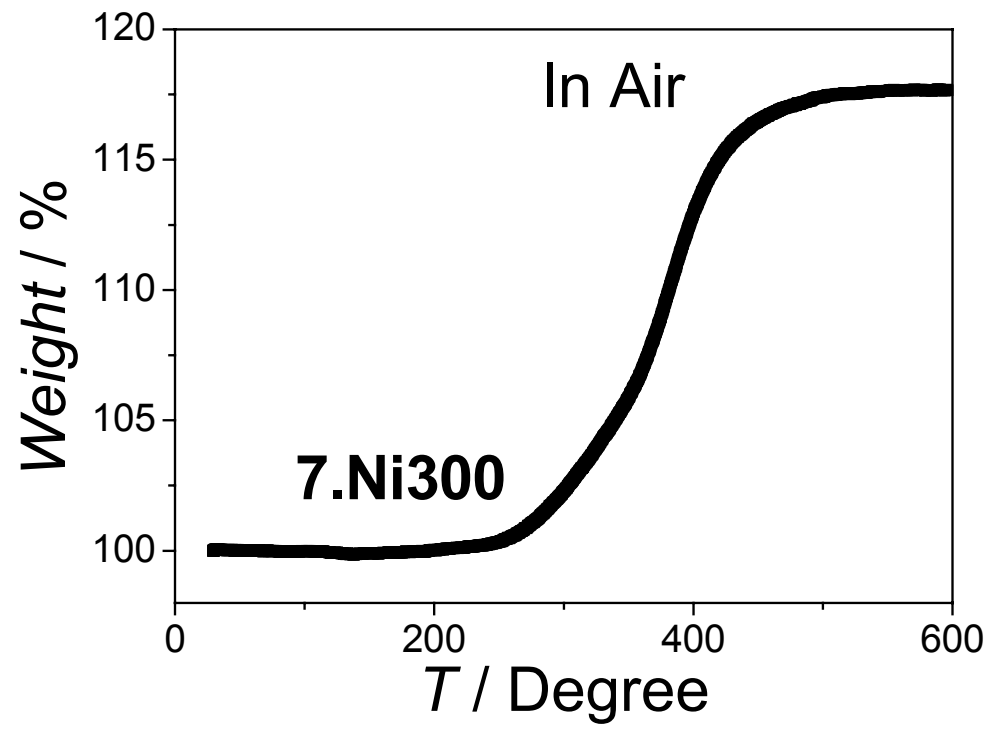

Figure S3 Thermogravimetric analysis (TGA) graph of 7·Ni300 from room temperature to $600{ }^{\circ} \mathrm{C}$. 


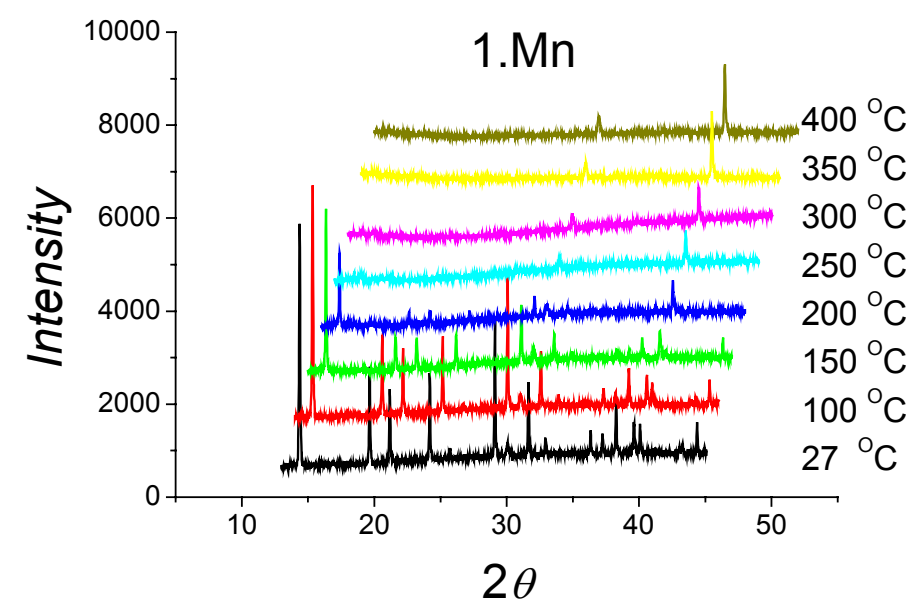

Figure S4 The variable-temperature XRD pattern of $\mathrm{Mn}(\mathrm{CHOO})_{3}\left[\mathrm{NH}_{2}\left(\mathrm{CH}_{3}\right)_{2}\right]$ from room temperature to $400{ }^{\circ} \mathrm{C}$. Scanning range: $13^{\circ}<2 \theta<45^{\circ}$. Peaks at $2 \theta=29.9^{\circ}$ and $39.4^{\circ}$ are the diffractions from the substrate

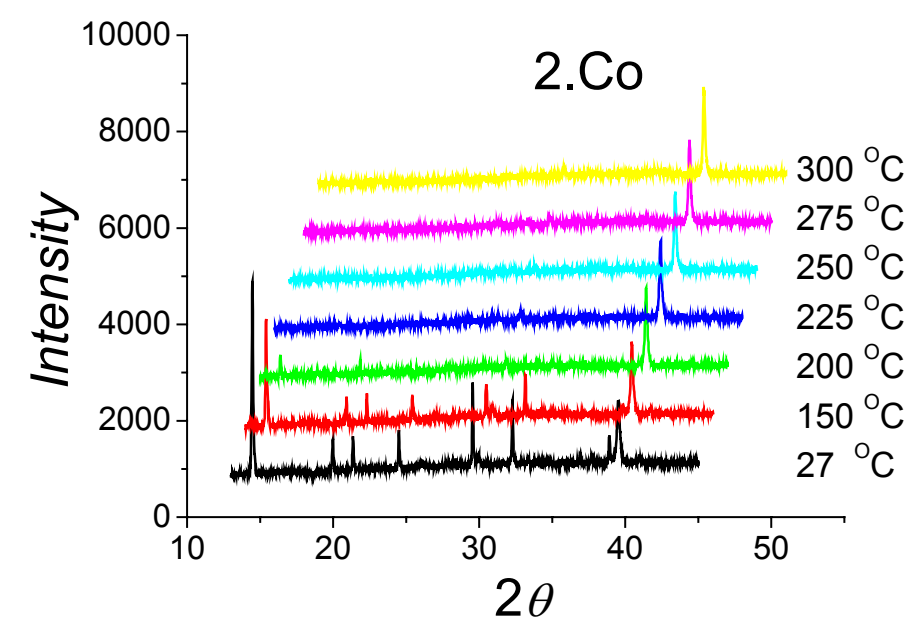

Figure S5 The variable-temperature XRD pattern of $\mathrm{Co}(\mathrm{CHOO})_{3}\left[\mathrm{NH}_{2}\left(\mathrm{CH}_{3}\right)_{2}\right]$ from room temperature to $300{ }^{\circ} \mathrm{C}$. Scanning range: $13^{\circ}<2 \theta<45^{\circ}$. Peaks at $2 \theta=29.9^{\circ}$ and $39.4^{\circ}$ are the diffractions from the substrate 


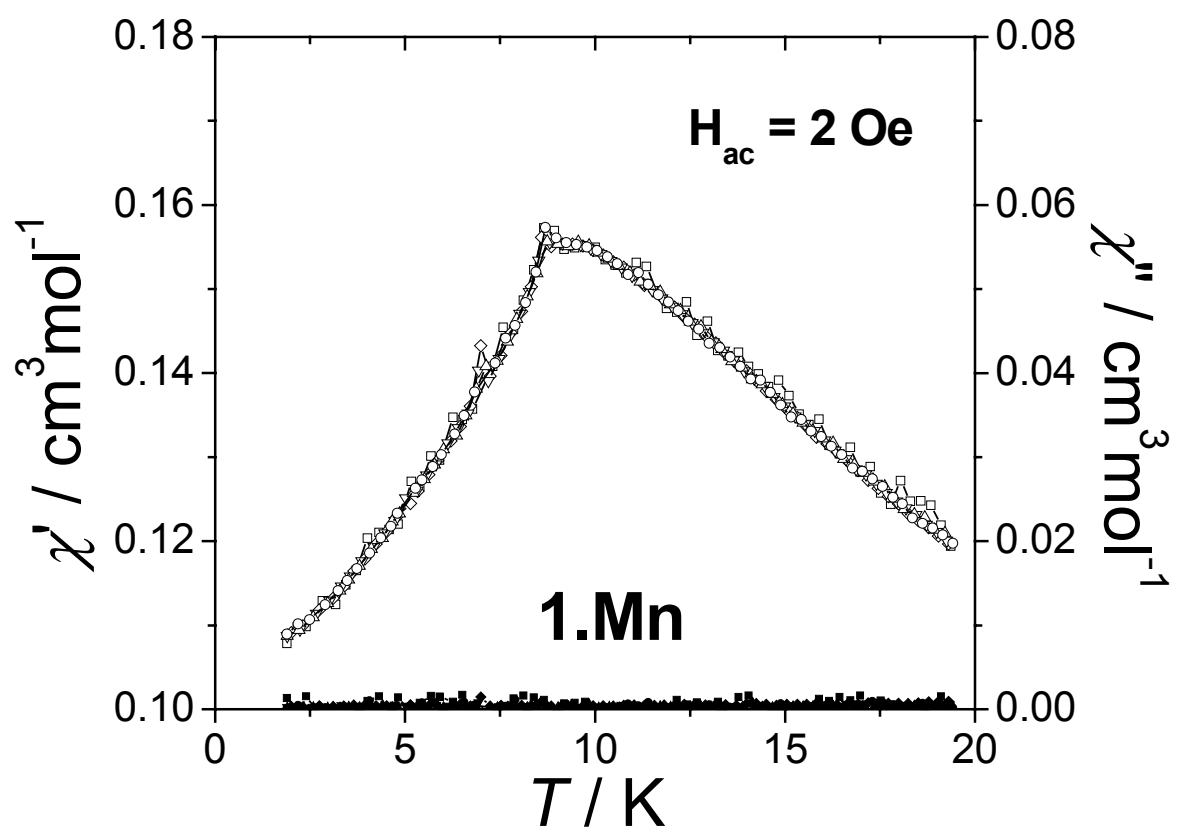

Figure S6 Real $\left(\chi_{\mathrm{M}^{\prime}}\right)$ and imaginary $\left(\chi_{\mathrm{M}^{\prime \prime}}\right) a c$ magnetic susceptibilities in zero applied $d c$ field and an $a c$ field of 2 Oe at different frequencies $(111,199,355,633,1111 \mathrm{~Hz})$ for $\mathbf{1} \cdot \mathbf{M n}$. 


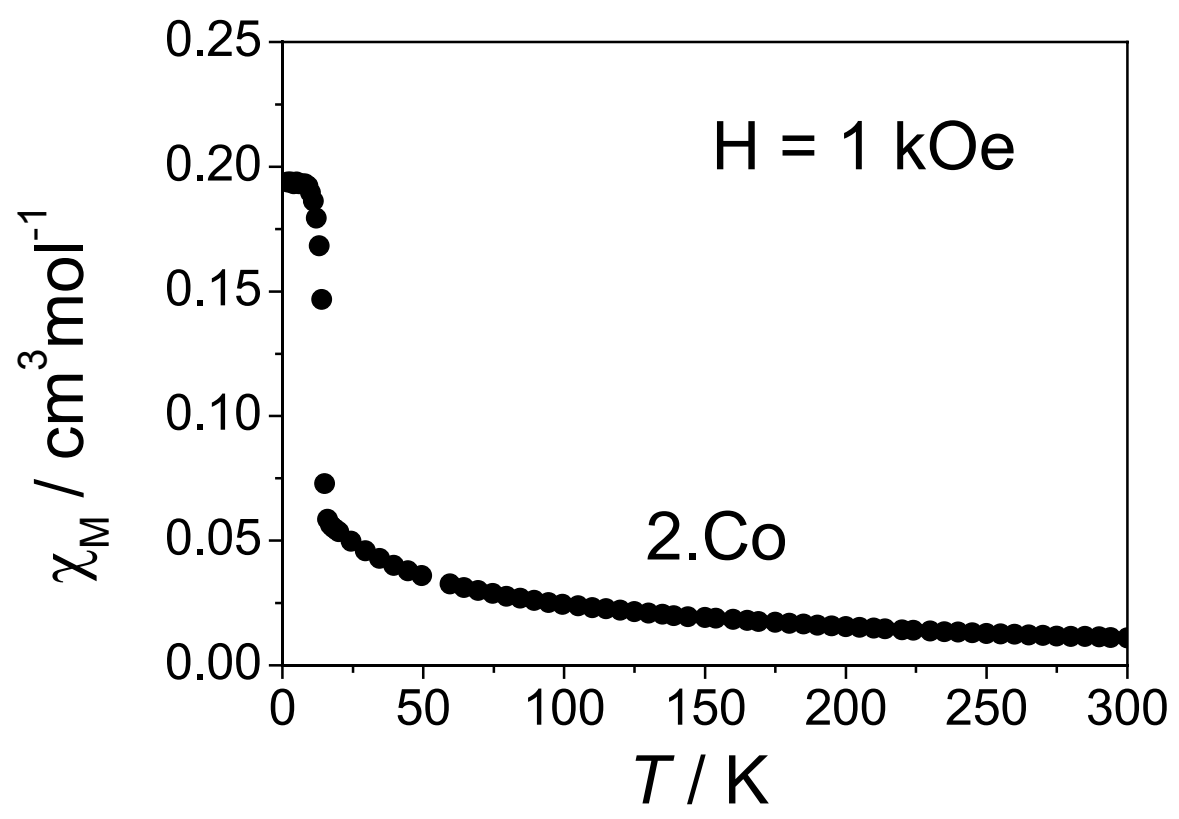

Figure S7 Temperature dependence of $\chi_{M}$ of $\mathbf{2} \cdot \mathbf{C o}$ at $\mathrm{H}=1000$ Oe from 2-300 K. 


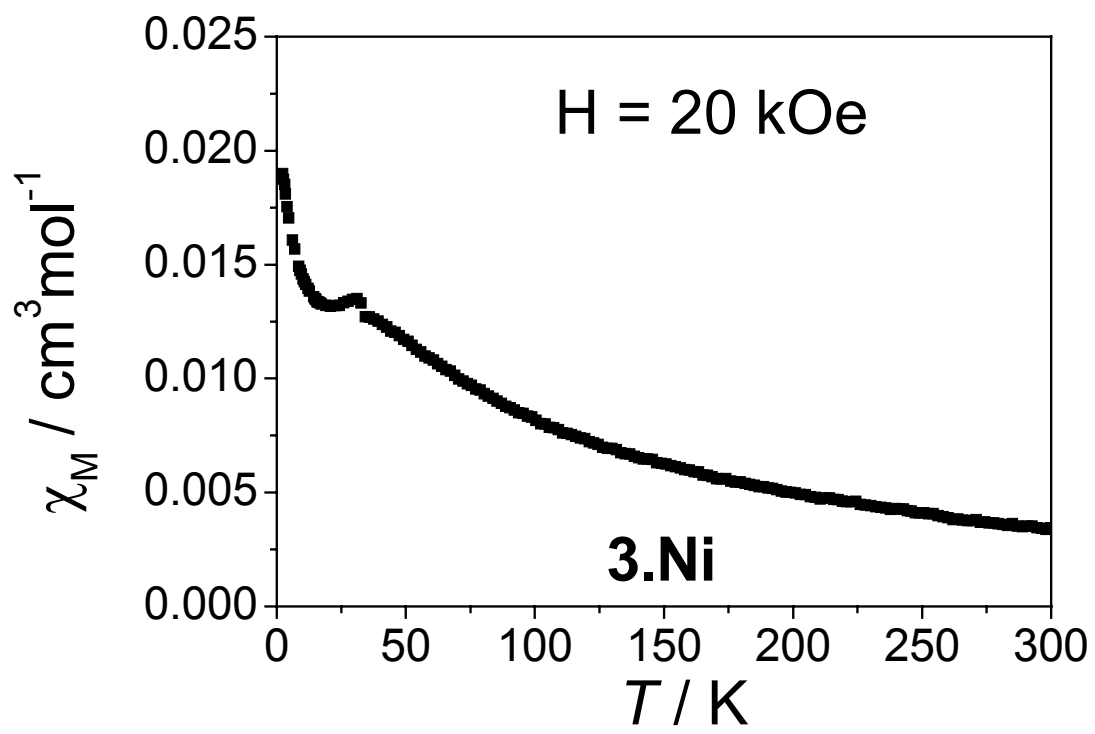

Figure S8 Temperature dependence of $\chi_{\mathrm{M}}$ of $\mathbf{3} \cdot \mathbf{N i}$ at $\mathrm{H}=20 \mathrm{kOe}$ from $2-300 \mathrm{~K}$ 


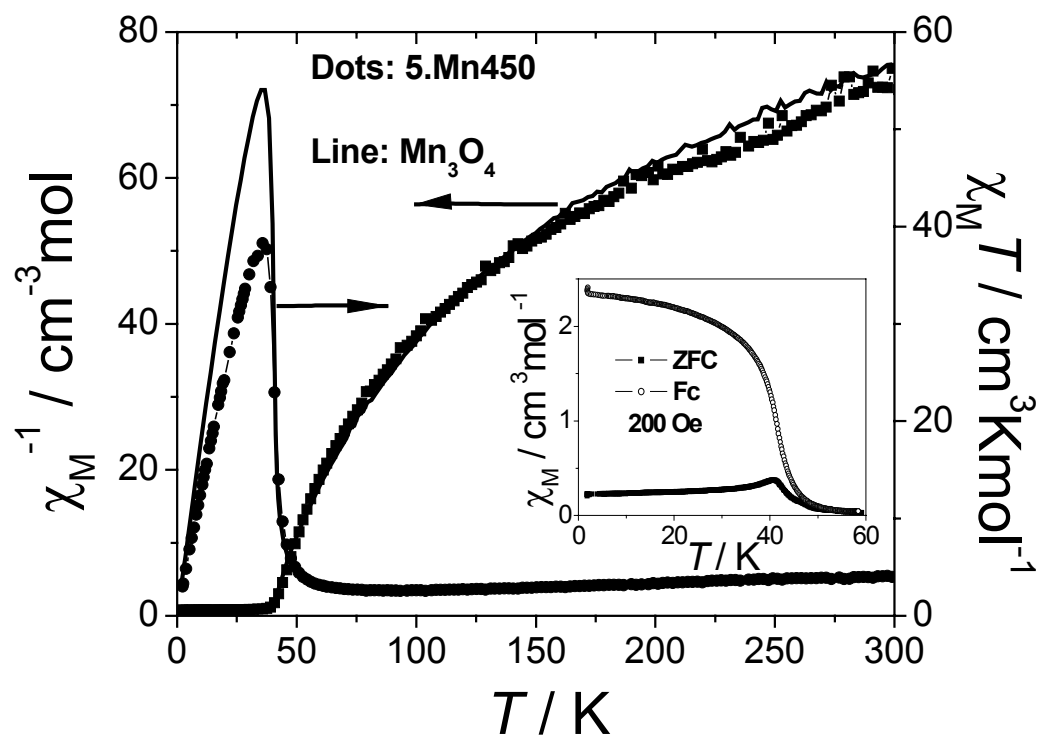

Figure S9 Temperature dependence of $\chi_{M} \mathrm{~T}$ and $\chi_{M}{ }^{-1}$ of $\mathbf{5} \cdot \mathbf{M n 4 5 0}$ (dots) and $\mathrm{Mn}_{3} \mathrm{O}_{4}$ (line) at $\mathrm{H}=5 \mathrm{kOe}$ from 2-300 K. Inset: ZFC and $\mathrm{FC}$ curves of $\mathbf{5} \cdot \mathbf{M n 4 5 0}$ at $\mathrm{H}=200 \mathrm{Oe}$. 


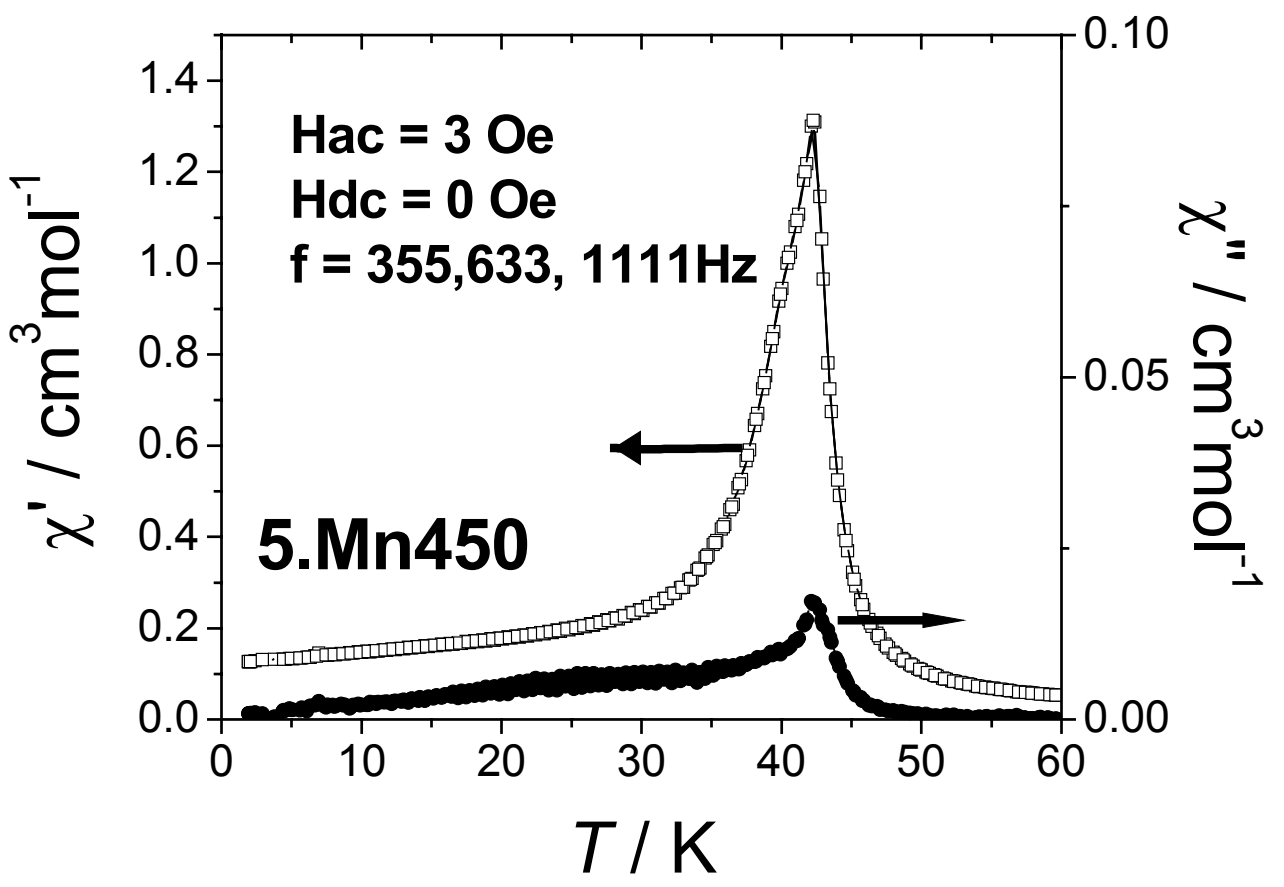

Figure S10 Real $\left(\chi_{M^{\prime}}\right)$ and imaginary $\left(\chi_{M^{\prime \prime}}\right)$ ac magnetic susceptibilities in zero applied $d c$ field and an $a c$ field of 3 Oe at different frequencies $(355,633,1111 \mathrm{~Hz})$ for $\mathbf{5} \cdot \mathbf{M n 4 5 0}$ 


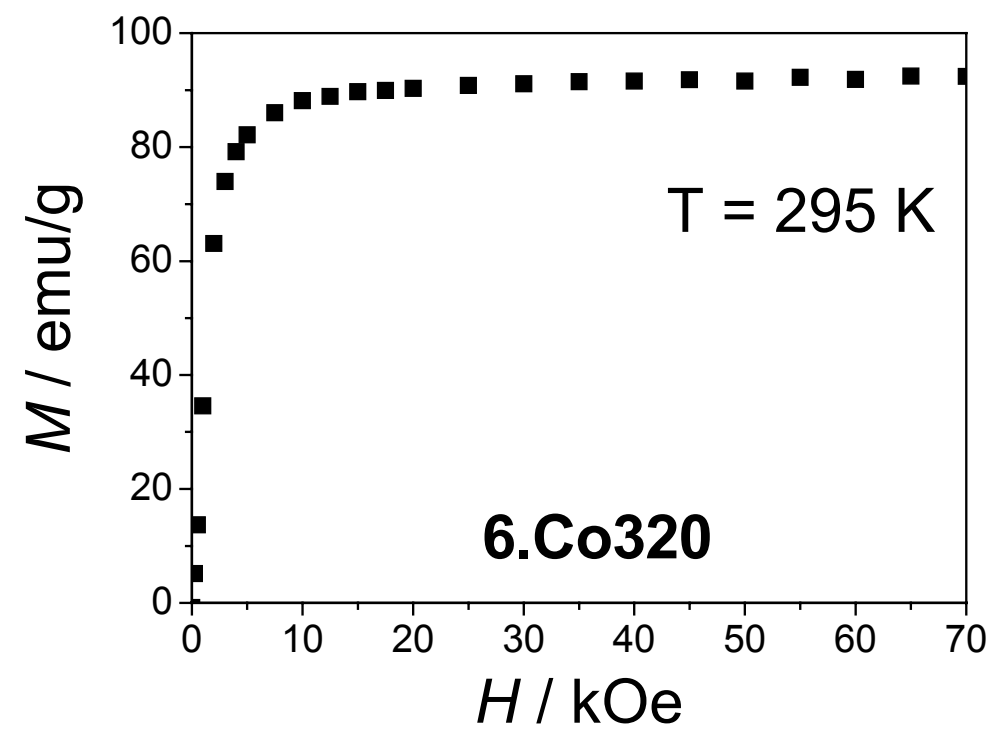

Figure S11 Field dependent isothermal magnetization $M(T, H)$ for $\mathbf{6 \cdot C 0 3 2 0}$ at $295 \mathrm{~K}$ from 0 to $70 \mathrm{kOe}$.

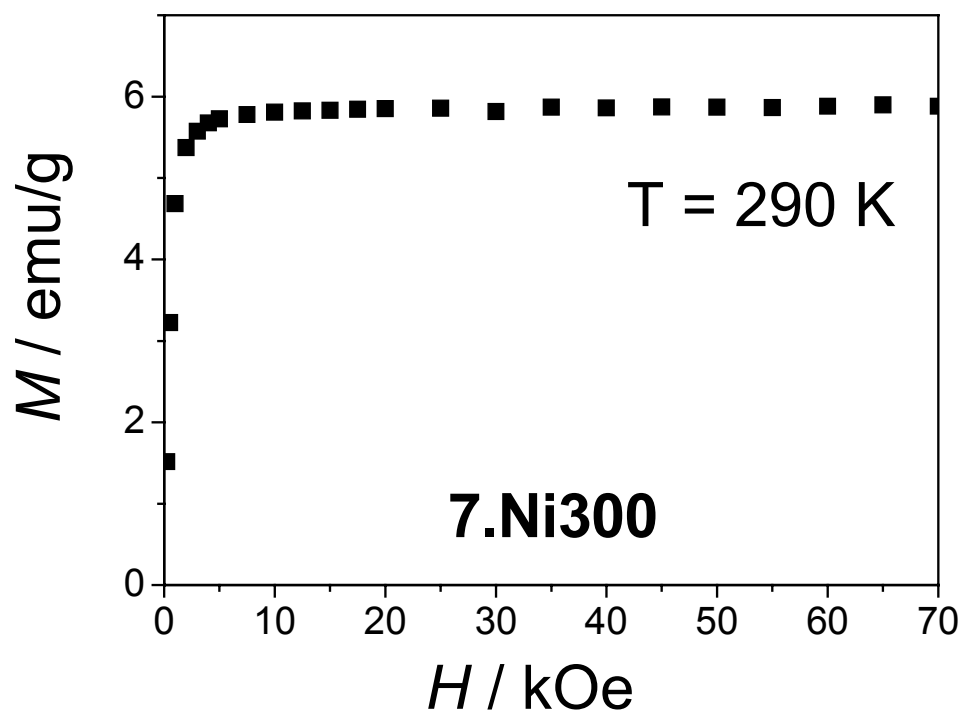

Figure S12 Field dependent isothermal magnetization $M(T, H)$ for $\mathbf{7} \cdot \mathbf{N i 3 0 0}$ at $290 \mathrm{~K}$ from 0 to $70 \mathrm{kOe}$. 